\title{
How do Orthopaedic Devices Change After Their Initial FDA Premarket Approval?
}

\author{
Andre M. Samuel BBA, Vinay K. Rathi BA, Jonathan N. Grauer MD, \\ Joseph S. Ross MD, MHS
}

Received: 29 June 2015/Accepted: 6 November 2015/Published online: 19 November 2015

(C) The Association of Bone and Joint Surgeons $\mathbb{R} 2015$

\begin{abstract}
Background The FDA approves novel, high-risk medical devices through the premarket approval (PMA) process based on clinical evidence supporting device safety and effectiveness. Devices subsequently may undergo postmarket modifications that are approved via one of several PMA supplement review tracks, usually without additional supporting clinical data. While orthopaedic devices cleared via the less rigorous $510(\mathrm{k})$ pathway have been studied previously, devices cleared through the PMA pathway and those receiving postmarket PMA supplements warrant further investigation.

Questions/purposes We asked: What are (1) the types of original orthopaedic devices receiving FDA PMA
\end{abstract}

approval, (2) the number and rate of postmarket device changes approved per device, (3) the types of PMA supplement review tracks used, (4) the types of device changes approved via the various review tracks, and (5) the number of device recalls and market withdrawals that have occurred for these devices?

Methods All original PMA-approved orthopaedic devices between January 1982 and December 2014 were identified in the publically available FDA PMA database. The number of postmarket device changes approved, the PMA supplement review track used, the types of postmarket changes, and any FDA recalls for each device were assessed.

Results Seventy original orthopaedic devices were approved via the FDA PMA pathway between 1982 and
One of the authors certifies that he (AMS), or a member of his or her immediate family, has or may receive payments or benefits, during the study period, an amount of less than USD 10,000 from Orthopaedic Trauma Association (Rosemont, IL, USA).

One of the authors certifies that he (JNG), or a member of his or her immediate family, has or may receive payments or benefits, during the study period, an amount of USD 10,000-USD 100,000 from Bioventus (Durham, NC, USA), an amount of USD 10,000-USD 100,000 from Harvard Clinical Research Institute (Boston, MA, USA), an amount of USD 10,000-USD 100,000 from ISTO Technologies (St Louis, MO, USA), an amount of less than USD 10,000 from Medtronic (Dublin, Ireland), an amount of USD 10,000USD 100,000 from Stryker (Mahwah, NJ, USA), an amount of less than USD 10,000 from Affinergy (Durham, NC, USA), an amount of USD 10,000-USD 100,000 from Alphatec (Carlsbad, CA), an amount of USD 10,000-USD 100,000 from DePuy (Raynham, MA, USA), an amount of less than USD 10,000 from Powered Research (Research Triangle Park, NC, USA), an amount of less than USD 10,000 from KCI (Mahwah, NJ, USA), an amount of less than USD 10,000 from Transgenomic (Omaha, NE, USA), an amount of less than USD 10,000 from Orthopaedic Trauma Association (Rosemont, IL, USA), and an amount of less than USD 10,000 from Smith and Nephew (London, UK).
One of the authors certifies that he (JSR), or a member of his or her immediate family, has or may receive payments or benefits, during the study period, an amount of USD 100,001-USD 1,000,000 from Medtronic, Inc. (Dublin, Ireland), and amount of USD 100,001-USD 1,000,000 from Johnson and Johnson (New Brunswick, NJ, USA), an amount of more than USD 1,000,001 from Centers for Medicare and Medicaid Services (Woodlawn, MD, USA), and an amount of USD 100,001-USD 1,000,000 from the US Food and Drug Administration (Silver Spring, MD, USA).

All ICMJE Conflict of Interest Forms for authors and Clinical Orthopaedics and Related Research ${ }^{\mathbb{R}}$ editors and board members are on file with the publication and can be viewed on request.

Clinical Orthopaedics and Related Research ${ }^{\mathbb{R}}$ neither advocates nor endorses the use of any treatment, drug, or device. Readers are encouraged to always seek additional information, including FDAapproval status, of any drug or device prior to clinical use. This study was performed at the Department of Orthopaedics and Rehabilitation; Yale School of Medicine, New Haven, CT, USA.

Electronic supplementary material The online version of this article (doi:10.1007/s11999-015-4634-x) contains supplementary material, which is available to authorized users. 
2014. These devices included 34 peripheral joint implants or prostheses, 18 spinal implants or prostheses, and 18 other devices or materials. These devices underwent a median 6.5 postmarket changes during their lifespan or 1.0 changes per device-year (interquartile range, 0.4-1.9). The rate of new postmarket device changes approved per active device, increased from less than 0.5 device changes per year in 1983 to just fewer than three device changes per year in 2014 , or an increase of 0.05 device changes per device per year in linear regression analysis $(95 \%$ CI, 0.040.07). Among the 765 total postmarket changes, 172 (22\%) altered device design or components. The majority of the design changes were reviewed via either the real-time review track $(\mathrm{n}=98 ; 57 \%)$, intended for minor design changes, or the 180-day review track $(n=71 ; 41 \%)$, intended for major design changes. Finally, a total of 12 devices had FDA recalls at some point during their lifespan, two being for hip prostheses with high revision rates. Conclusions Relatively few orthopaedic devices undergo the FDA PMA process before reaching the market. Orthopaedic surgeons should be aware that high-risk medical devices cleared via the FDA's PMA pathway do undergo considerable postmarket device modification after reaching the market, with potential for design "drift," ie, shifting away from the initially tested and approved device designs. Clinical Relevance As the ultimate end-users of these devices, orthopaedic surgeons should be aware that even among high-risk medical devices approved via the FDA's PMA pathway, considerable postmarket device modification occurs. Continued postmarket device monitoring will be essential to limit patient safety risks.

\section{Introduction}

According to the 1976 Medical Device Amendments Act [24], all novel "high-risk" medical devices must be approved by the U.S. FDA through the Premarket Approval

\footnotetext{
A. M. Samuel, J. N. Grauer ( $\square$ )

Department of Orthopaedics and Rehabilitation, Yale School of Medicine, 800 Howard Ave, New Haven, CT 06510, USA

e-mail: jonathan.grauer@yale.edu
}

A. M. Samuel, V. K. Rathi

Yale School of Medicine, New Haven, CT, USA

\section{J. S. Ross}

Department of Internal Medicine, Yale School of Medicine, New Haven, CT, USA

\section{J. S. Ross}

Department of Health Policy and Management, Yale School of Public Health, New Haven, CT, USA
(PMA) process [28]. These high-risk, or FDA Class III devices, include any that "support or sustain human life, are of substantial importance in preventing impairment of human health, or present a potential, unreasonable risk of illness or injury," [28] rather than Class I or Class II devices which pose less risk to patients (Table 1). Unlike the alternative $510(\mathrm{k})$ Premarket Notification pathway, which is designed to expedite clearance of low- and moderate-risk devices through the demonstration of "substantial equivalence" to existing predicate devices, the PMA pathway requires manufacturers to provide original clinical data that support device safety and effectiveness before device clearance [28].

However, several high-risk Class III devices have been cleared via the less-rigorous $510(\mathrm{k})$ pathway, owing to a legal provision in the Medical Device Amendments Act [24], allowing certain classes of high-risk devices to be exempt from the PMA process. As a result, these 510(k)cleared devices may reach patients without prior clinical testing. In the field of orthopaedics this includes metal-onmetal hip prostheses, cement spacers, and spinal pedicle fixation systems. Owing to criticism of this regulatory loophole, Congress directed the FDA to either reclassify these exempt devices as Class I or Class II or retroactively require PMAs [4]. Although the process is still ongoing, in coming years we likely will see increased use of the PMA pathway for approval of high-risk orthopaedic devices.

Once a device is approved through the PMA pathway, PMA supplement applications can be submitted to the FDA for postmarket devices changes [27]. Various types of PMA supplement review tracks exist (Table 2), each intended for different types of device modifications (changes in device design, labeling, production, and postmarket testing) and requiring varying amounts of clinical or preclinical data before approval.

Despite the evidentiary requirements of the PMA pathway, there has been concern that the clinical studies forming the basis of PMA applications may lack adequate strength and be prone to bias $[3,5,6,12,13,20,34]$. This is especially worrisome for implantable devices that cannot be easily removed or discontinued. For example the PMAapproved Sprint Fidelis implantable cardioverter-defibrillator lead (Medtronic, Dublin, Ireland) was found to have increased risk of fracture only after 3 years on the market and 268,000 implants [25].

These concerns also extend to postmarket device changes made after initial PMA approval [11, 12]. Although the expectation is that individual postmarket device changes will have a limited effect on device safety or effectiveness, cumulative iterations of device changes may cause "drift" away from the originally approved device design. A previous study of PMA supplements found that cardiac implantable electronic devices 
Table 1. FDA device classes

\begin{tabular}{llc}
\hline FDA device class & Examples & Regulatory controls \\
\hline Class I (low risk) & Bone tamp, screw driver, rongeur, cast saw, compression device & $\begin{array}{c}\text { General controls (most are exempt from } \\
510(\mathrm{k}) \text { Premarket Notification) }\end{array}$ \\
Class II (moderate risk) & $\begin{array}{c}\text { Intramedullary nails, ORIF plates, screws, arthroplasty components, } \\
\text { spinal fixation implants, vertebral body replacements, bone void fillers }\end{array}$ & $\begin{array}{c}\text { General controls, 510(k) Premarket } \\
\text { Notification (few are exempt) }\end{array}$ \\
Class III (high risk) & $\begin{array}{c}\text { Alternative bearing THA systems, hip resurfacing systems, mobile } \\
\text { bearing TKA systems, total ankle replacements, total disc replacements }\end{array}$ & $\begin{array}{c}\text { General controls, Premarket Approval } \\
\text { (few are exempt) }\end{array}$ \\
\hline
\end{tabular}

ORIF $=$ open reduction internal fixation.

Table 2. Types of PMA supplement review tracks

\begin{tabular}{|c|c|}
\hline Supplement Review Track & Description \\
\hline 180-day track & $\begin{array}{l}\text { Formally introduced in } 1986 \\
\text { Reviewed by FDA staff or, in some cases, expert panel } \\
\text { Requires preclinical data and, in some cases, clinical data } \\
\text { Intended for design and labeling changes affecting safety and efficacy, } \\
\text { eg, approval of new acetabular shell to be used with ceramic liner in hip prosthesis }\end{array}$ \\
\hline Special track & $\begin{array}{l}\text { Formally introduced in } 1986 \\
\text { Reviewed by FDA staff } \\
\text { Requires no specific new data } \\
\text { Intended for labeling changes meant to enhance device safety, } \\
\text { eg, revisions to patient and physician labeling or surgical technique manual }\end{array}$ \\
\hline Panel track & $\begin{array}{l}\text { Formally introduced in } 1990 \\
\text { Reviewed by subject matter expert panel } \\
\text { Requires substantial new clinical data in most cases } \\
\text { Intended for labeling changes expanding indications for use or removing contraindications, } \\
\text { eg, expanded indications for intervertebral body fusion device for one- or two- level fusions }\end{array}$ \\
\hline Real-time process & $\begin{array}{l}\text { Formally introduced in } 1997 \\
\text { Reviewed by FDA staff } \\
\text { Requires preclinical data } \\
\text { Intended for minor changes in design, software, or labeling, } \\
\text { eg, addition of a tamp extractor instrument to a total hip prosthesis system }\end{array}$ \\
\hline 30-day notice & $\begin{array}{l}\text { Formally introduced in } 1997 \\
\text { Reviewed by FDA staff } \\
\text { Requires no specific new data } \\
\text { Intended for changes in manufacturing processes that may affect device safety and efficacy, } \\
\text { eg, change in component supplier or sterilization testing procedure }\end{array}$ \\
\hline 135-day review & $\begin{array}{l}\text { Formally introduced in } 1997 \\
\text { Reviewed by FDA staff } \\
\text { Requires new information per FDA request } \\
\text { Intended for } 30 \text {-day notice applications requiring further review before clearance, } \\
\text { eg, change in polishing process and equipment for total hip prosthesis system }\end{array}$ \\
\hline
\end{tabular}

underwent more than 30 postmarket changes to device design or labeling that often were not supported by new clinical data [21]. This "drift" phenomenon is similar to what has been described for metal-on-metal hip implants, which have long received clearance through the 510(k) pathway [1,9]. The ASR ${ }^{\mathrm{TM}} \mathrm{XL}$ Acetabular Cup System
(DePuy Inc, Raynham, MA, USA), for example, first cleared in 2008, was recalled from the market in 2010 because of high revision rates [1,7]. This implant received original $510(\mathrm{k})$ clearance based on six predicate devices, each with unique design features that were combined in the $\mathrm{ASR}^{\mathrm{TM}} \mathrm{XL}$. These six devices did not undergo PMA 
approval, but instead received $510(\mathrm{k})$ clearance based on a long lineage of more than 60 predicate devices during 50 years, including three now-discontinued devices.

The field of orthopaedic surgery relies heavily on implants, which can have a high-cost of failure to the patient [18]. In the past, high-risk orthopaedic devices cleared through the $510(\mathrm{k})$ pathway have been shown to lack adequate evidence supporting safety and effectiveness [16], and therefore undergo recalls [1]. Although orthopaedic devices cleared via the $510(\mathrm{k})$ pathway have been studied [1, 7, 22], numerous commonly used, high-risk orthopaedic devices currently require PMA approval and may undergo postmarket changes via PMA supplements, including alternative bearing THA systems, hip resurfacing systems, and mobile bearing total knee systems. In addition, there have been reports of PMA-approved devices being recalled from the market, such as certain sizes of the Birmingham Hip ${ }^{\mathrm{TM}}$ Resurfacing $\left(\mathrm{BHR}^{\circledR}\right.$ ) System (Smith \& Nephew, London, UK) and the New Jersey LCS ${ }^{\circledR}$ Total Knee System (DePuy Inc), both recalled in 2015 owing to high revision rates [2, 23]. As PMA-approved orthopaedic devices have not been analyzed in the literature, to our knowledge, the current study characterizes all orthopaedic devices approved through the FDA PMA pathway (since passage of the 1976 Medical Device Amendments Act, which formalized evaluation and market clearance of medical devices by the FDA) and all postmarket device changes subsequently cleared for these devices.

We therefore asked, what are (1) the types of original orthopaedic devices receiving FDA approval through the PMA process, (2) the number and rate of postmarket device changes cleared per device, (3) the types of PMA supplement review tracks used, (4) the types of device changes approved via the various review tracks, and (5) the number of device recalls and market withdrawals that have occurred for these devices?

\section{Materials and Methods}

A retrospective, cross-sectional analysis was conducted of the publically accessible FDA PMA database (assessed December 2014) containing records of all original and supplemental PMA approvals [33]. Supplement approvals may include newly marketed products that represent modifications to existing PMA-approved devices. All PMA supplement approvals are linked in the database to the original PMA application for the initial version of the device to create a lineage of device iterations.

All FDA PMA devices that were approved between January 1982 (year of first PMA-approved orthopaedic device) through December 2014 and assigned to the FDA Orthopaedic and Rehabilitation Devices Panel were identified [32].
All these devices were designated as high-risk, or FDA Class III, at the time of application. The type of PMA application was determined based on coding in the FDA database. All applications were characterized by date of approval.

In addition, device recall history was characterized by searching the FDA Medical Device Recalls Database, containing all device recalls issued since November 1, 2002, for each PMA application number to determine any device recall dates.

For analysis of the types of original orthopaedic devices receiving FDA PMA approval, the total number of devices in each device category was simply computed and reported. Device type was determined by using FDA-designated product classification codes and categorized by us in the following groups: peripheral joint implant/prosthesis, spinal joint implant/prosthesis, and other orthopaedic device. The numbers of original devices approved via the PMA pathway were determined for each year. Linear regression was used to determine the change in annual PMA approvals with time.

For analysis of postmarket device changes, the number of postmarket changes approved via PMA supplements for active device was determined. The median (and interquartile range) postmarket device changes per device and per deviceyear were reported, as certain outlier devices showed substantially greater numbers of postmarket changes, skewing a calculation of the mean. The devices with the greatest total postmarket changes and greater rate of postmarket changes per year were reported. Linear regression was used to determine the change in annual rate of postmarket changes with time.

For analysis of the types of PMA supplement review tracks, the number of PMA supplements approved each year was broken down by review tracks. The percentage of each review track type from all PMA supplements was determined for each review track type since its inception. The FDA currently uses six PMA supplement review tracks (Table 2). Changes that alter device design or components are intended for review via the 180-day track (major design changes) or the real-time track (minor design change). Changes in production processes (eg, sterilization) are intended for review via the 30-day notice track. The FDA may convert process changes to the 135-day review track when additional supporting information is required. Changes in device labeling are intended for review via the panel track (changes expanding indications or removing contraindications for a device) or the special track (labeling that enhances device safety). Certain supplements cleared before 1990 are unclassified in a specific review track in the PMA database.

For analysis of the types of postmarket device changes, the types of postmarket device changes were characterized for all 180-day track, real time, 30-day notice, 135-day review, special track, and panel track supplements. Types of device changes were reported in the PMA database by 
the FDA using the following categories (Appendix 1 . Supplemental material is available with the online version of $\mathrm{CORR}^{\circledR}$ ): Instructions labeling change, Indications labeling change, Other labeling change, Minor design change, Component design change, Other design change, Manufacturing production change, Other production change, Location change, Postapproval study protocol change, and Other device change. As an added analysis the most common type of supplement review track used to approve design changes was determined.

Finally, for analysis of the number of device recalls and market withdrawals that have occurred for these devices, all recalls and withdrawals were simply assessed and reported. Reasons for market withdrawal are not given in the PMA database. Device recall history was characterized by searching the FDA Medical Device Recalls Database [31], containing all device recalls issued from November 1, 2002 to September 1, 2015, for each PMA application number to determine any device recall dates. Recall date, recall classification, and reason for recall were assessed. The FDA classifies medical device recalls in three classes [29]. A Class I recall is a "situation in which there is a reasonable probability that the use of, or exposure to, a violative product will cause serious adverse health consequences or death." A Class II recall is a "situation in which use of, or exposure to, a violative product may cause temporary or medically reversible adverse health consequences or where the probability of serious adverse health consequences is remote." A Class III recall is a "situation in which use of, or exposure to, a violative product is not likely to cause adverse health consequences." Devices recalled specifically owing to high revision rates were identified. Market withdrawals are reported in the FDA PMA database. The mean time from original PMA approval to market withdrawal was computed for devices that were withdrawn from the market.

All statistical analyses were performed using Stata $^{\circledR}$ version 13.0 (StataCorp, LP, College Station, TX, USA). Statistical tests were two-tailed and a probability less than 0.05 was considered statistically significant.

\section{Results}

Orthopaedic Devices Receiving PMA Approval

A total of only 70 orthopaedic devices have been cleared via the FDA PMA pathway since passage of the 1976 Medical Device Amendments Act [24]. These devices included 34 peripheral joint implants/prostheses (Table 3), 18 spinal implants/prostheses (Table 4), and 18 other devices or materials (Table 5). In linear regression analysis (Fig. 1), the rate of original PMA device approvals increased by 0.07 per year $(95 \% \mathrm{CI}, 0.01-0.13 ; \mathrm{p}=0.023$; $\mathrm{R}^{2}=0.1549$ ).

\section{Postmarket Changes for PMA-approved Devices}

A total of 765 postmarket changes were approved for these 70 devices through December 2014. The median number of postmarket device changes approved per device via PMA supplements was 6.5 (interquartile range [IQR], 3-13), or 0.9 PMA supplements approved per active device-year (IQR, 0.4-1.8). The rate of new postmarket device changes approved per active device, increased from less than 0.5 device changes per year in 1983 to just fewer than three device changes per year in 2014 (Fig. 2). In linear regression analysis the rate of new postmarket device changes approved per active device, increased by 0.05 device changes per year (95\% CI, 0.04-0.07; $\mathrm{p}<0.001 ; \mathrm{R}^{2}=0.6235$ ).

For peripheral joint prostheses, the median number of postmarket changes per device was 7.5 (IQR, 3-14), or 0.9 changes (IQR, 0.4-1.9) per active device-year. For spinal implants/prostheses, the median number of postmarket changes per device was seven (IQR, 3-13), or 1.4 changes (IQR, 0.9-1.8) per active device-year. For other devices, the median number of postmarket changes per device was five (IQR, $0-11$ ), or 0.6 changes (IQR, $0.0-1.5$ ) per active device-year.

The New Jersey LCS $^{\circledR}$ Total Knee System had the highest total number of postmarket changes, with 135 device changes approved during its 30.5-year lifespan, or 4.4 device changes per device-year (Fig. 3). The highest rate of postmarket device changes per device-year was for the Ceramax ${ }^{\circledR}$ Ceramic Hip System (DePuy Inc), with 4.5 supplements approved per device-year during a 4.4-year lifespan.

\section{PMA Supplement Review Tracks}

Use of different types of PMA supplement review tracks has changed with time (Fig. 3). The 180-day track was the most common type of supplement review track used since the PMA program began, accounting for more than $34 \%$ of all supplements for orthopaedic devices. Since their introduction in 1997, the 30-day notice and 135-day reviews, intended for process changes and not requiring any new clinical data, have accounted for $37 \%$ of all PMA supplements approved since that time. Of the original 30-day notice applications that eventually were approved, $47 \%$, or 118 applications, were converted to 135 -day review track after the FDA deemed the information supporting the change to be inadequate. Only seven panel track supplements have been approved for orthopaedic devices. The 


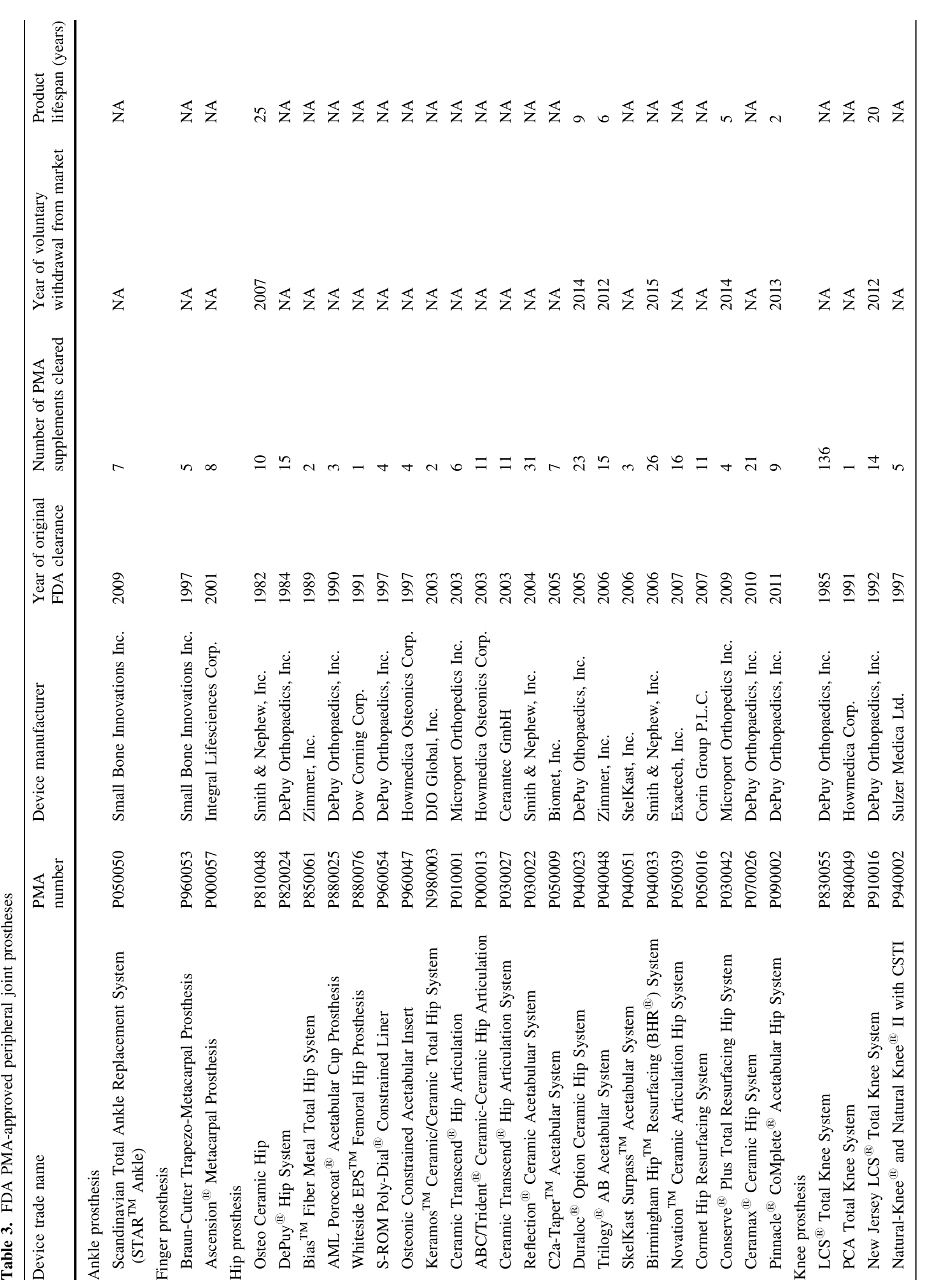




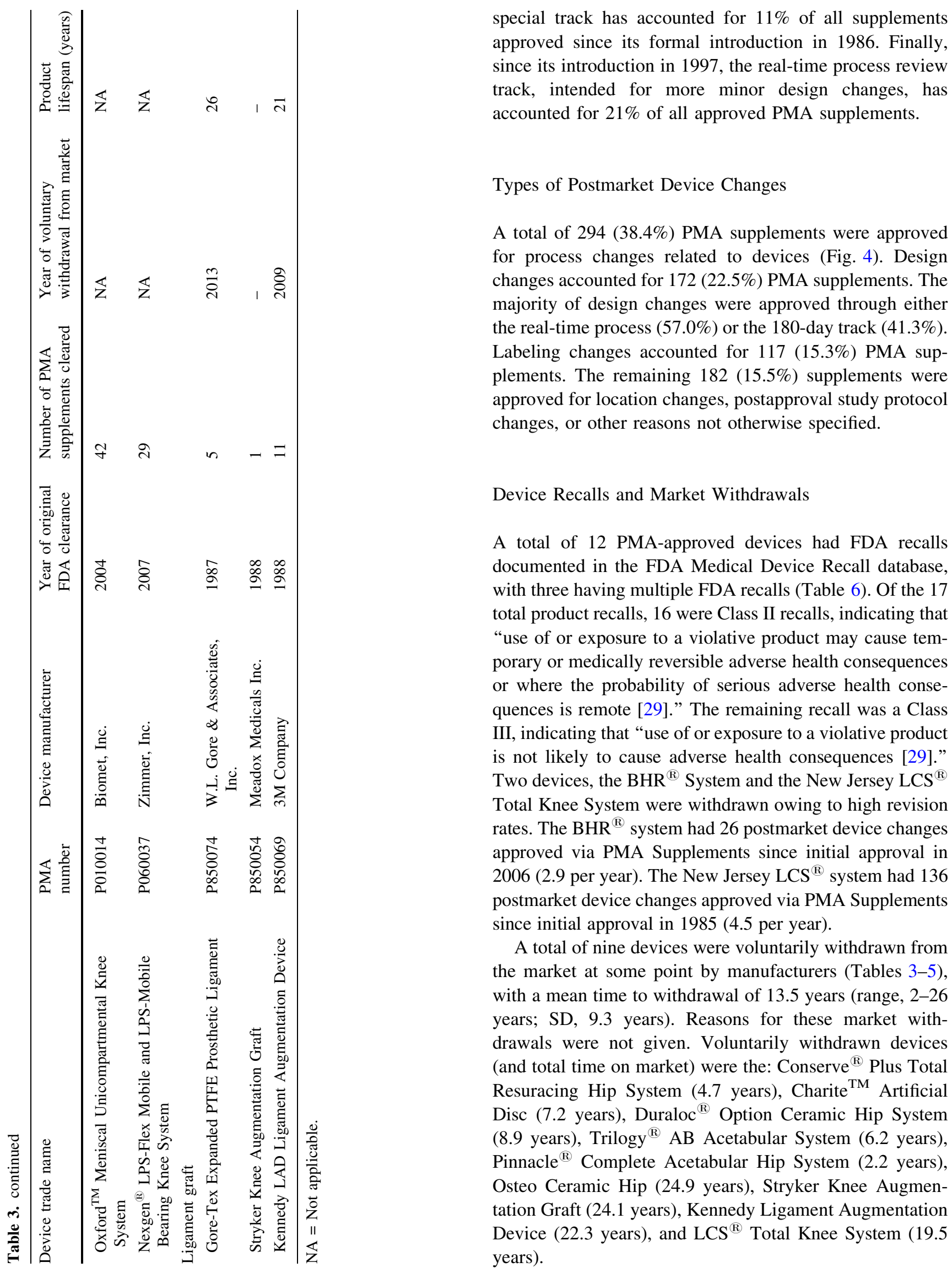


Table 4. FDA PMA-approved spinal implants and prostheses

\begin{tabular}{|c|c|c|c|c|c|c|}
\hline Device trade name & PMA number & Device manufacturer & $\begin{array}{l}\text { Year of original } \\
\text { FDA clearance }\end{array}$ & $\begin{array}{l}\text { Number of } \\
\text { PMA } \\
\text { supplements } \\
\text { cleared }\end{array}$ & $\begin{array}{l}\text { Year of } \\
\text { withdrawal } \\
\text { from market }\end{array}$ & $\begin{array}{l}\text { Product } \\
\text { lifespan } \\
\text { (years) }\end{array}$ \\
\hline \multicolumn{7}{|l|}{ Intervertebral body fusion devices } \\
\hline $\begin{array}{l}\text { Ray Threaded Fusion Cage }{ }^{\mathrm{TM}} \text { with } \\
\text { Instrumentation }\end{array}$ & P950019 & Stryker Corp. & 1996 & 17 & NA & NA \\
\hline Bak $^{\circledR}$ Interbody Fusion System & P950002 & Zimmer, Inc. & 1996 & 14 & NA & NA \\
\hline Inter Fix ${ }^{\mathrm{TM}}$ Threaded Fusion Device & P970015 & $\begin{array}{l}\text { Medtronic Sofamor } \\
\text { Danek USA, Inc. }\end{array}$ & 1999 & 23 & NA & NA \\
\hline $\begin{array}{l}\text { Brantigen I/F Cage }{ }^{\circledR} \text { used with VSP } \\
\text { Spine Plates and Pedicle Screws }\end{array}$ & P960025 & DePuy Spine, Inc. & 1999 & 12 & NA & NA \\
\hline Bak/Cervicle ${ }^{\circledR}$ Interbody Fusion System & P980048 & Sulzer Spine-Tech & 2001 & 4 & NA & NA \\
\hline Affinty ${ }^{\mathrm{TM}}$ Cage System & P000028 & $\begin{array}{l}\text { Medtronic Sofamor } \\
\text { Danek USA, Inc. }\end{array}$ & 2002 & 8 & NA & NA \\
\hline \multicolumn{7}{|l|}{ Intervertebral disc prostheses } \\
\hline Charité $^{\mathrm{TM}}$ Artificial Disc & P040006 & DePuy Spine, Inc. & 2004 & 6 & 2012 & 8 \\
\hline Prodisc $^{\mathbb{R}}$-L Total Disc Replacement Device & P050010 & Synthes Holding AG & 2006 & 15 & NA & NA \\
\hline Prodisc $^{\circledR}$ TM-C Total Disc Replacement & P070001 & Synthes Holding AG & 2007 & 12 & NA & NA \\
\hline Prestige $^{\circledR}$ Cervical Disc System & P060018 & $\begin{array}{l}\text { Medtronic Sofamor } \\
\text { Danek USA, Inc. }\end{array}$ & 2007 & 4 & NA & NA \\
\hline Bryan ${ }^{\mathbb{R}}$ Cervical Disc Prosthesis & P060023 & $\begin{array}{l}\text { Medtronic Sofamor } \\
\text { Danek USA, Inc. }\end{array}$ & 2009 & 5 & NA & NA \\
\hline Nuvasive ${ }^{\mathbb{R}}$ PCM Cervical Disc System & P100012 & Nuvasive, Inc. & 2012 & 6 & NA & NA \\
\hline Secure $^{\circledR}$-C Artificial Cervical Disc System & P100003 & Globus Medical Inc. & 2012 & 4 & NA & NA \\
\hline $\begin{array}{l}\text { Mobi-C }{ }^{\circledR} \text { Cervical Disc Prosthesis } \\
\text { (Two-Level Indication) }\end{array}$ & P110009 & LDR Spine USA, Inc. & 2013 & 8 & NA & NA \\
\hline $\begin{array}{l}\text { Mobi-C }{ }^{\mathbb{R}} \text { Cervical Disc Prosthesis } \\
\text { (One-Level Indication) }\end{array}$ & P110002 & LDR Spine USA, Inc. & 2013 & 8 & NA & NA \\
\hline Prestige ${ }^{\mathbb{R}}$ LP Cervical Disc & P090029 & $\begin{array}{l}\text { Medtronic Sofamor } \\
\text { Danek USA, Inc. }\end{array}$ & 2014 & 1 & NA & NA \\
\hline \multicolumn{7}{|l|}{ Spinous process spacers } \\
\hline $\begin{array}{l}\text { X-Stop }{ }^{\mathbb{R}} \text { Interspinous Process } \\
\text { Decompression System }\end{array}$ & P040001 & $\begin{array}{l}\text { Medtronic Sofamor } \\
\text { Danek USA, Inc. }\end{array}$ & 2005 & 19 & NA & NA \\
\hline Coflex ${ }^{\mathbb{R}}$ Interlaminar Stabilization Device & P110008 & Paradigm Spine, LLC & 2012 & 3 & NA & NA \\
\hline
\end{tabular}

$\mathrm{NA}=$ not applicable.

\section{Discussion}

The FDA PMA process is currently the most rigorous pathway for high-risk medical devices to reach the market. Because of additional innovation or safety reasons, these devices often may require modifications after initial approval and marketing. The PMA supplement pathway allows these postmarket device changes to be approved in a more rapid fashion than formal PMA application. However, only limited new supporting evidence is required for these supplements compared with original PMA device clearances, and many postmarket device changes are approved without any new clinical data. As a result, these PMA supplements allow for potential device "drift" away from the originally approved device design. As device "drift" without new supporting clinical data in the 510(k) premarket notification process has been implicated in the high-profile recall of the $\mathrm{ASR}^{\mathrm{TM}} \mathrm{XL}$ Acetabular Cup System [1], there is potential for patient safety risks with inadequate oversight of postmarket device changes. With implanted orthopaedic devices, the cost of device failure can be especially high for patients, and there is a need for surgeons to understand how devices are changing after initial FDA PMA approval. In light of this need, we reviewed all PMA-approved orthopaedic devices in the publically available FDA PMA database from 1982 to 2014. Only 70 original orthopaedic devices have been approved via the PMA pathway, a finding which may be 
Table 5. Other FDA PMA-approved orthopaedic devices

\begin{tabular}{|c|c|c|c|c|}
\hline Device trade name & PMA number & Device manufacturer & $\begin{array}{l}\text { Year of original } \\
\text { FDA clearance }\end{array}$ & $\begin{array}{l}\text { Number of PMA } \\
\text { supplements cleared }\end{array}$ \\
\hline \multicolumn{5}{|l|}{ Hyaluronic acid } \\
\hline Synvisc-One ${ }^{\circledR}$ & P940015 & Genzyme Corp. & 1997 & 23 \\
\hline Hyalgan ${ }^{\circledR}$ & P950027 & Fidia Farmaceutici SPA & 1997 & 11 \\
\hline Supartz $^{\mathrm{TM}}$ Dispo & P980044 & Seikagaku Corp. & 2001 & 2 \\
\hline Euflexxa $^{\mathbb{R}}$ (1\% Sodium Hyaluronate) & P010029 & Ferring Pharmaceuticals, Inc. & 2004 & 6 \\
\hline Orthovisc ${ }^{\circledR}$ High Molecular Weight Hyaluronan & P030019 & Anika Therapeutics, Inc. & 2004 & 12 \\
\hline Gel-One $^{\circledR}$ & P080020 & Seikagaku Corp. & 2011 & 13 \\
\hline Sinovial $^{\circledR}(0.8 \%$ Sodium Hyaluronate $)$ & P110005 & Ibsa Institut Biochimique SA & 2014 & 1 \\
\hline Monovisc $^{\mathbb{R}}$ & P090031 & Anika Therapeutics, Inc. & 2014 & 3 \\
\hline \multicolumn{5}{|l|}{ Bone cement } \\
\hline Palacos ${ }^{\circledR}$ R Bone Cement & P810020 & Smith \& Nephew Richard, Inc. & 1984 & 6 \\
\hline DePuy 1 Bone Cement & P960001 & DePuy Orthopaedics Inc. & 1997 & 9 \\
\hline \multicolumn{5}{|l|}{ Bone graft and filler } \\
\hline Alveoform ${ }^{\mathrm{TM}}$ Biograft & P860012 & Collagen Corp. & 1988 & 5 \\
\hline $\begin{array}{l}\text { Pro Osteon }{ }^{\circledR} \text { Implant } 500 \text { Hydroxyapatite } \\
\text { Bone Void Filler }\end{array}$ & P860005 & Interpore Intl. & 1992 & 1 \\
\hline Collagraft Bone Graft Substitute & P900039 & Neucoll, Inc. & 1993 & 1 \\
\hline $\begin{array}{l}\text { Infuse }^{(\mathbb{R}} \text { Bone Graft/ LT-Cage }{ }^{\mathbb{R}} \text { Lumar } \\
\text { Tapered Fusion Device }\end{array}$ & P000058 & Medtronic Sofamor Danek USA, Inc. & 2002 & 49 \\
\hline Infuse ${ }^{(B)}$ Bone Graft & P000054 & Medtronic Sofamor Danek USA, Inc. & 2004 & 17 \\
\hline \multicolumn{5}{|l|}{ Shock wave generator } \\
\hline Orbasone $^{\mathrm{TM}}$ Pain Relief System & P040039 & Orthometrix, Inc. & 2005 & 1 \\
\hline \multicolumn{5}{|l|}{ Bone growth stimulator } \\
\hline Orthopak ${ }^{\circledR}$ Bone Growth Stimulator & P850022 & Biolectron, Inc. & 1989 & 6 \\
\hline $\begin{array}{l}\text { OL1000/OL10000 SC and Spinalogic } \\
\text { Bone Growth Stimulators }\end{array}$ & P910066 & DJ Orthopedics, LLC & 2012 & 1 \\
\hline
\end{tabular}

unexpected for the device-heavy field of orthopaedic surgery. These devices underwent a median 0.9 PMA postmarket device changes per device-year, but the rate of postmarket changes increased steadily during the past 20 years. The use of the various supplement review tracks has shifted with the introduction of quicker review tracks, however. In addition, two PMA-approved joint prostheses were recently recalled owing to high-revision rates, both having numerous postmarket changes approved via PMA supplements.

The current study has important limitations to consider. First, earlier records of PMA supplements (earlier than 1986) do not have information regarding the type of supplement review tracks or detail on the type of device change made. However, this represents only a minority of supplement review tracks for orthopaedic devices (most occurred after 1986; Fig. 3). Next, for more recent records, there is no detail regarding whether new clinical or preclinical data were provided to the FDA. This does not meaningfully affect our analysis because the specific data requirements for most PMA supplements are known, based on the type of supplement review tracks used. However, for 180-day tracks, this requirement is variable. Since 2010, the FDA has not published review memos for select 180day supplements specifying the amount and type of new clinical or preclinical data submitted. However, no review memos were published or are available for orthopaedic devices.

\section{Orthopaedic Devices Receiving PMA Approval}

In the device- and implant-driven field of orthopaedic surgery, it is surprising that only 70 original devices have received PMA approval since 1976. For comparison, by December 2015, more than 169 different Class III metalon-metal hip prostheses had been cleared through the $510(\mathrm{k})$ pathway, which requires only proof of similarity or "substantial equivalence" to a previously cleared device, and not original clinical testing [30]. In addition, 18 of the 28 FDA device codes for hip prostheses are classified as Class II, which do not require PMA approval (Table 7). 


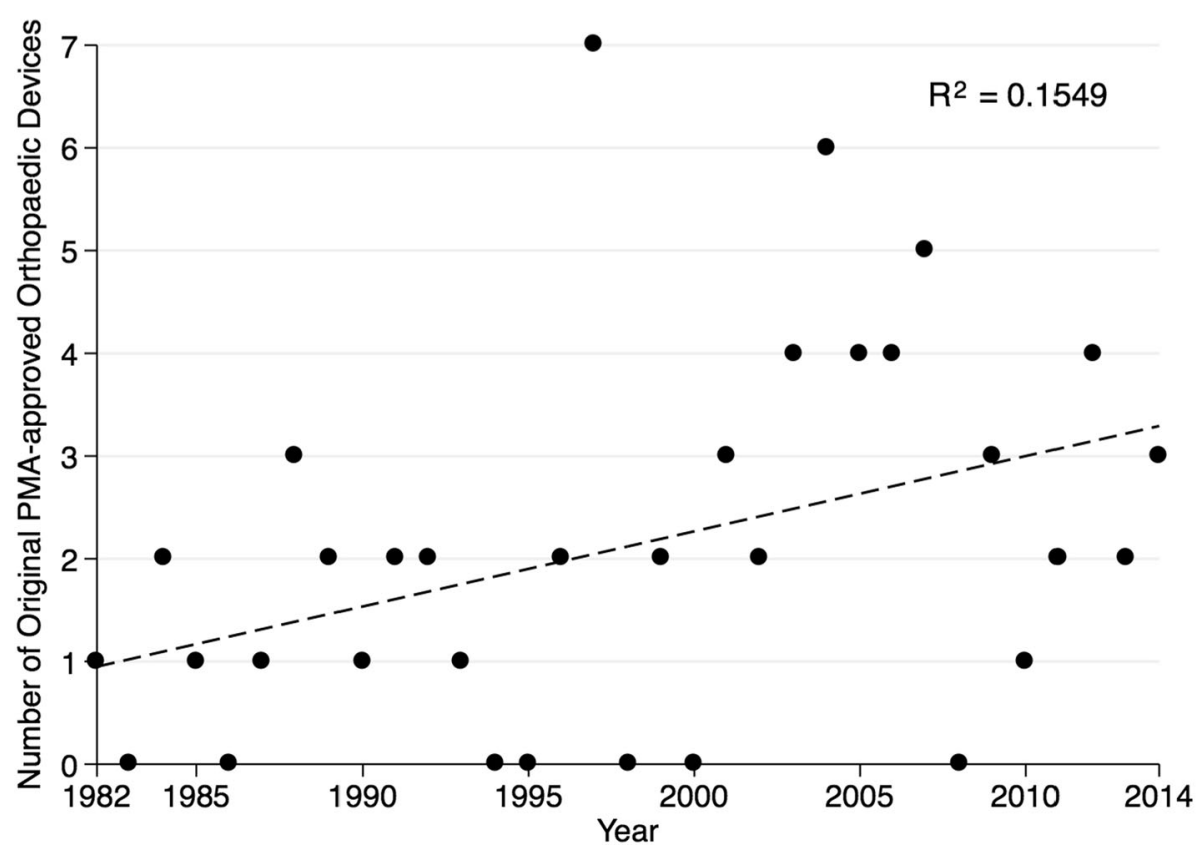

Fig. 1 The number of original Class III orthopaedic devices approved via premarket approval (PMA) has increased with time. Best-fit linear regression function is shown with $\mathrm{R}^{2}$.

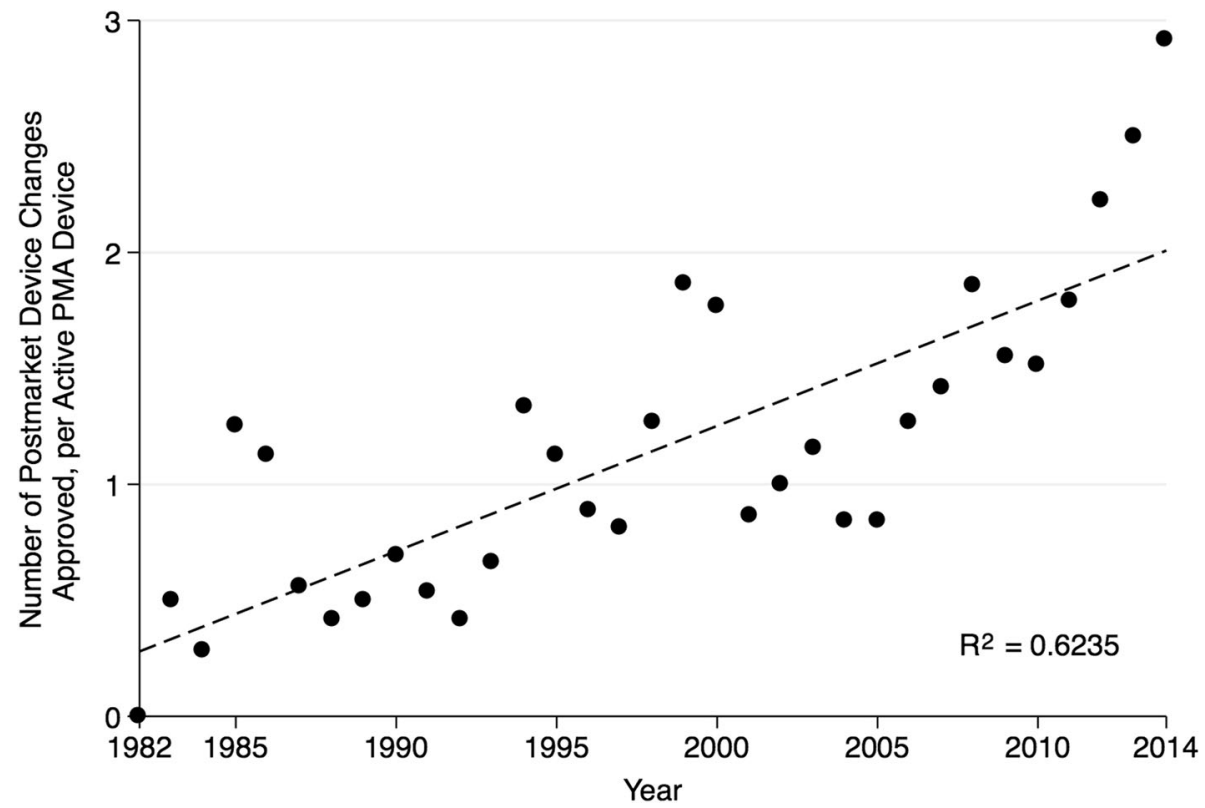

Fig. 2 The number PMA supplements approved per active orthopaedic PMA-approved device has increased with time. Best-fit linear regression function is shown with $\mathrm{R}^{2}$. PMA = premarket approval.

The regulatory exemption for certain Class III devices and widespread classification of many orthopaedic prostheses as Class II (moderate risk) devices contribute to the low utilization of PMA approval for orthopaedic devices compared with $510(\mathrm{k})$ clearances. Even in other fields, the 510(k) premarket notification process historically has been the most widely used pathway to market for high-risk devices. Rome et al. [21] reported on 77 original PMA approvals for cardiac implantable electronic devices between 1979 and 2012. Garber [9] reported that from 2003 to 2007, a total of 228 Class III devices were cleared for marketing via the $510(\mathrm{k})$ process versus 170 device receiving PMA-approval. However, owing to criticism of the $510(\mathrm{k})$ pathway in the wake of high-profile metal-on- 


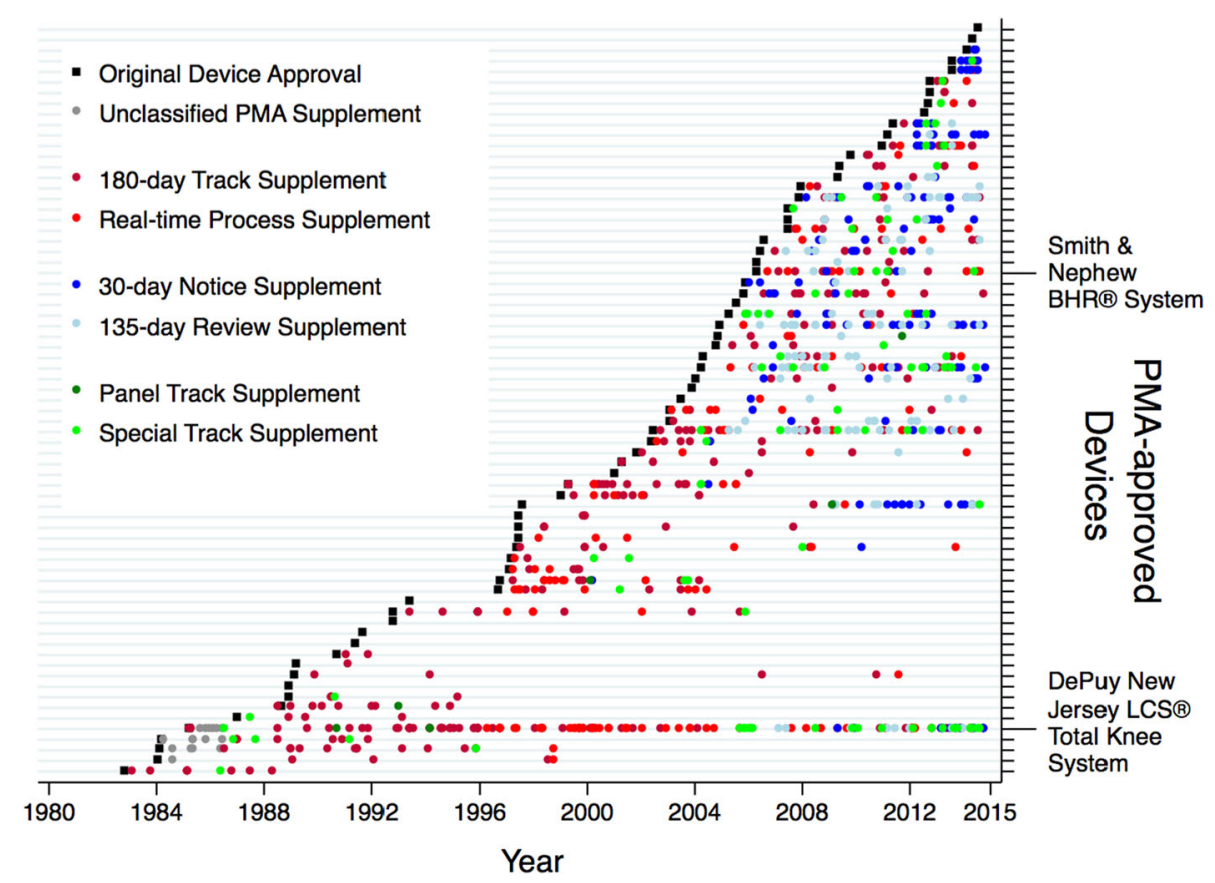

Fig. 3 There is substantial variability in the use of the different types of PMA supplement review tracks with time and in the use of PMA supplements between different devices. PMA = premarket approval.

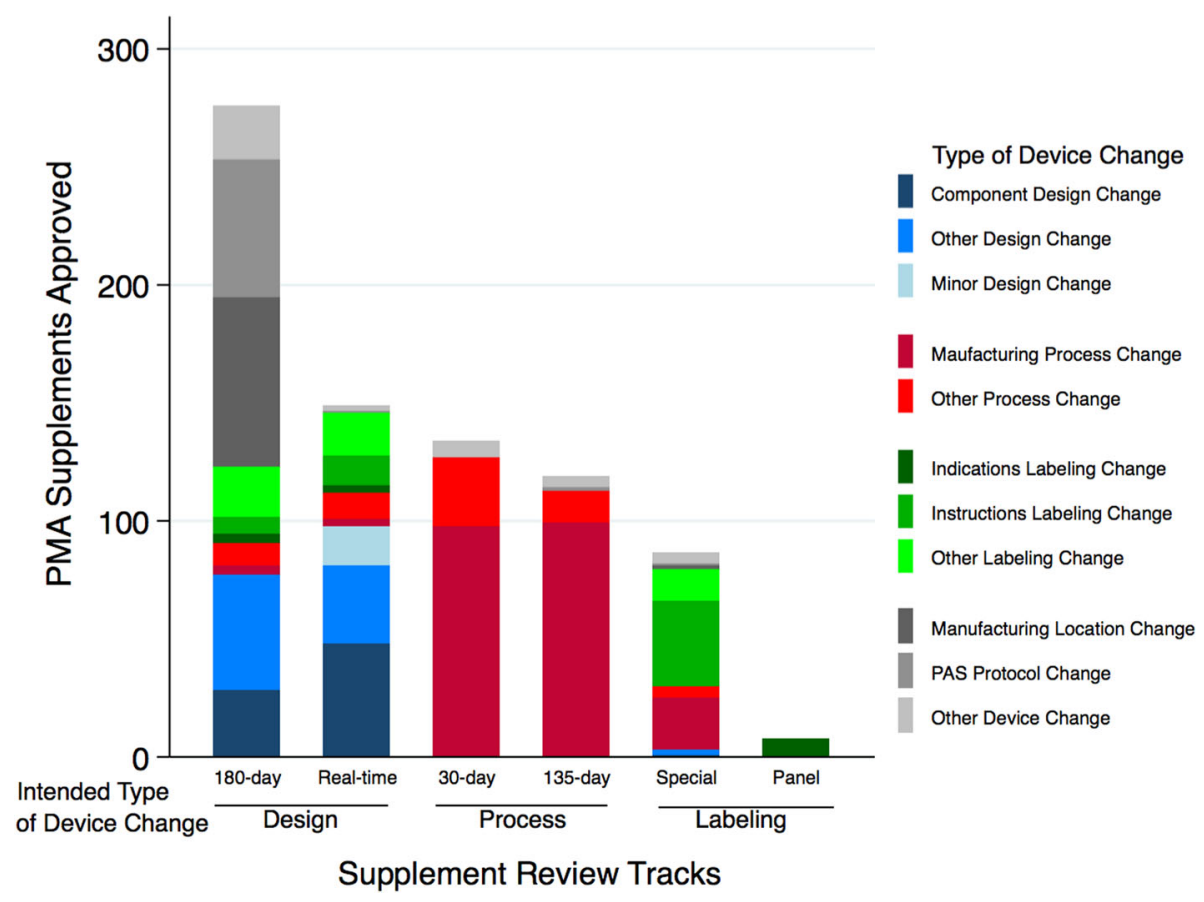

Fig. 4 The types of device changes approved vary by PMA supplement review track. PMA = premarket approval; PAS = postapproval study.

metal hip implant failures, transitioning away from the $510(\mathrm{k})$ pathway in the near future was encouraged [4]. In 2009 the FDA launched the 515 Program Initiative to transition all high-risk devices to the PMA pathway [26]. Through this program, the FDA plans to review 515 Class
III devices that originally underwent only 510(k) premarket notification, rather than PMA-approval. Each device either will be reclassified as a Class I or Class II device, or a formal PMA will be required. The expected increase in PMA pathway use ultimately will result in more supporting 


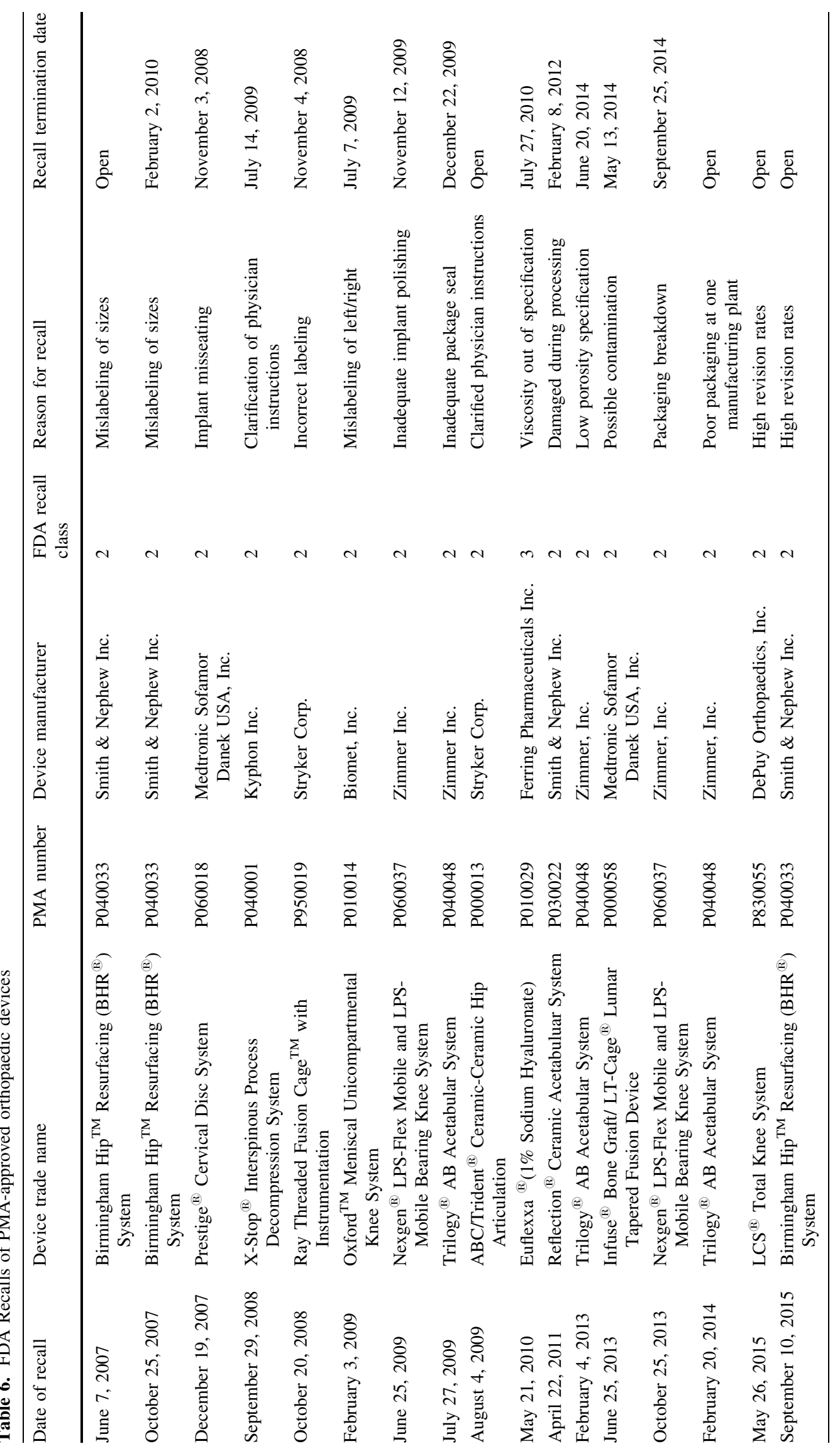


Table 7. FDA classification of hip prostheses

\begin{tabular}{|c|c|c|c|}
\hline $\begin{array}{l}\text { FDA device } \\
\text { class }\end{array}$ & $\begin{array}{l}\text { FDA-designated } \\
\text { product code* }\end{array}$ & FDA device classification description & $\begin{array}{l}\text { FDA regulatory } \\
\text { process }\end{array}$ \\
\hline \multirow{18}{*}{$\begin{array}{l}\text { Class II hip } \\
\text { prostheses }\end{array}$} & KWZ & Prosthesis, Hip, Constrained, Cemented Or Uncemented, Metal/Polymer & $510(\mathrm{k})$ \\
\hline & PBI & $\begin{array}{l}\text { Prosthesis, Hip, Constrained, Cemented Or Uncemented, Metal/Polymer, + } \\
\text { Additive }\end{array}$ & $510(\mathrm{k})$ \\
\hline & JDG & Prosthesis, Hip, Femoral Component, Cemented, Metal & $510(\mathrm{k})$ \\
\hline & KXA & Prosthesis, Hip, Femoral, Resurfacing & $510(\mathrm{k})$ \\
\hline & KWL & Prosthesis, Hip, Hemi-, Femoral, Metal & $510(\mathrm{k})$ \\
\hline & LZY & Prosthesis, Hip, Hemi-, Femoral, Metal Ball & $510(\mathrm{k})$ \\
\hline & KWY & Prosthesis, Hip, Hemi-, Femoral, Metal/Polymer, Cemented Or Uncemented & $510(\mathrm{k})$ \\
\hline & KMC & Prosthesis, Hip, Semi-Constrained, Composite/Metal & $510(\mathrm{k})$ \\
\hline & OQI & $\begin{array}{l}\text { Prosthesis, Hip, Semi-Constrained, Cemented, Metal/Ceramic/Polymer + } \\
\text { Additive, Porous Uncemented }\end{array}$ & $510(\mathrm{k})$ \\
\hline & $\mathrm{OQH}$ & $\begin{array}{l}\text { Prosthesis, Hip, Semi-Constrained, Cemented, Metal/Polymer + Additive, } \\
\text { Cemented }\end{array}$ & $510(\mathrm{k})$ \\
\hline & OQG & $\begin{array}{l}\text { Prosthesis, Hip, Semi-Constrained, Cemented, Metal/Polymer, + Additive, } \\
\text { Porous, Uncemented }\end{array}$ & $510(\mathrm{k})$ \\
\hline & MAY & $\begin{array}{l}\text { Prosthesis, Hip, Semi-Constrained, Metal/Ceramic/Polymer, Cemented Or Non- } \\
\text { Porous Cemented, Osteophilic Finish }\end{array}$ & $510(\mathrm{k})$ \\
\hline & LZO & $\begin{array}{l}\text { Prosthesis, Hip, Semi-Constrained, Metal/Ceramic/Polymer, Cemented Or Non- } \\
\text { Porous, Uncemented }\end{array}$ & $510(\mathrm{k})$ \\
\hline & JDI & Prosthesis, Hip, Semi-Constrained, Metal/Polymer, Cemented & $510(\mathrm{k})$ \\
\hline & LPH & Prosthesis, Hip, Semi-Constrained, Metal/Polymer, Porous Uncemented & $510(\mathrm{k})$ \\
\hline & LWJ & Prosthesis, Hip, Semi-Constrained, Metal/Polymer, Uncemented & $510(\mathrm{k})$ \\
\hline & MEH & $\begin{array}{l}\text { Prosthesis, Hip, Semi-Constrained, Uncemented, Metal/Polymer, Non-Porous, } \\
\text { Calicum-Phosphate }\end{array}$ & $510(\mathrm{k})$ \\
\hline & MBL & Prosthesis, Hip, Semi-Constrained, Uncemented, Metal/Polymer, Porous & $510(\mathrm{k})$ \\
\hline \multirow{10}{*}{$\begin{array}{r}\text { Class III hip } \\
\text { prostheses }\end{array}$} & KXD & Prosthesis, Hip, Constrained, Metal & PMA \\
\hline & KWB & Prosthesis, Hip, Hemi-, Acetabular, Cemented, Metal & PMA \\
\hline & KXB & Prosthesis, Hip, Pelvifemoral Resurfacing, Metal/Polymer & PMA \\
\hline & OCG & Prosthesis, Hip, Pelvifemoral Resurfacing, Metal/Polymer, Uncemented & PMA \\
\hline & JDL & Prosthesis, Hip, Semi-Constrained (Metal Cemented Acetabular Component) & Exemption - 510(k) \\
\hline & KWA & Prosthesis, Hip, Semi-Constrained (Metal Uncemented Acetabular Component) & Exemption - 510(k) \\
\hline & $\mathrm{OVO}$ & Prosthesis, Hip, Semi-Constrained, Ceramic-On-Metal Articulation & PMA \\
\hline & LPF & Prosthesis, Hip, Semi-Constrained, Metal/Ceramic/Ceramic, Cemented & PMA \\
\hline & MRA & $\begin{array}{l}\text { Prosthesis, Hip, Semi-Constrained, Metal/Ceramic/Ceramic/Metal, Cemented Or } \\
\text { Uncemented }\end{array}$ & PMA \\
\hline & NXT & Prosthesis, Hip, Semi-Constrained, Metal/Metal, Resurfacing & PMA \\
\hline
\end{tabular}

* FDA-designated product codes are three-character unique identifiers used by the FDA to classify devices in unique product categories.

evidence for original high-risk devices and improved monitoring of postmarket device changes by the FDA and the public, as FDA tracking of changes implemented through the $510(\mathrm{k})$ pathway is considerably less organized [10].

\section{Postmarket Changes for PMA-approved Devices}

A median 6.5 postmarket device changes were approved per original orthopaedic PMA device, or 1.0 change per deviceyear. In the only other analysis of PMA supplement-approved postmarket device changes, Rome et al. [21] reported a median of 50 device changes per cardiac implantable electronic device, or 2.6 changes per device-year-more than observed for orthopaedic devices. These differences may reflect the high rate of software modifications that may occur during the lifespan of a cardiac implantable electronic device. Although our results suggest that orthopaedic devices undergo relatively fewer postmarket changes, experience with devices cleared via the $510(\mathrm{k})$ pathway suggests otherwise. The previously noted $\mathrm{ASR}^{\mathrm{TM}} \mathrm{XL}$ Acetabular Cup System first received 510(k) clearance in 
2008. This clearance for this metal-on-metal hip prosthesis was issued without supporting clinical data, but rather was based on substantial equivalence to six predicate devices that each had unique features that were combined in the $\mathrm{ASR}^{\mathrm{TM}} \mathrm{XL}$ (the metal-on-metal articulation, porous bone ingrowth surface, and large femoral head sizes). These six devices also were never clinically tested before their marketing, and similarly received $510(\mathrm{k})$ clearance owing to substantial equivalence to prior devices. It ultimately was found that the $\mathrm{ASR}^{\mathrm{TM}}$ XL was derived from a lineage of 95 $510(\mathrm{k})$ devices cleared during 50 years, including several that since have been withdrawn from the market [1]. This substantial lack of supporting clinical data was implicated when the $\mathrm{ASR}^{\mathrm{TM}} \mathrm{XL}$ was later recalled owing to high revision rates. Although this degree of device "drift" is substantially greater than seen with most PMA devices, the most-heavily modified orthopaedic device under the PMA system, the New Jersey LCS ${ }^{\circledR}$ Total Knee System, did have 135 postmarket supplements approved during 30 years. This prosthesis was similarly recalled by the FDA in 2015 owing to high revision rates when used with a native, nonresurfaced patella. Although the specific relationship between postmarket device modifications and revision rates warrants further investigation, there is clear potential for device "drift," similar to the $510(\mathrm{k})$ pathway, with modifications being rapidly marketed to and adopted by providers without new supporting clinical evidence.

\section{PMA Supplement Review Tracks}

The types of supplement review tracks used appear to have changed with time with the introduction of quicker review tracks such as the 30-day notice. The most commonly used supplement review track since the start of the program has been the 180-day track (36\%), intended for significant device modifications [27], while the 30-day notice and 135-day review, intended for minor manufacturing process changes, have become more common. For cardiac implantable electronic devices, the most commonly used supplement review track since the start of the PMA program has been the 30-day notice $(47 \%)$ [21]. With the introduction of new supplement review tracks, corresponding increases in the total rates of supplements cleared also has been observed. Notably, the increases in postmarket changes approved per active device during the early 2000s (for orthopaedic devices and cardiac implantable electronic devices) seem to correspond with increased use of the newly available 30-day notice for production process changes, which requires limited supporting evidence before approval. Interestingly, the New Jersey LCS $^{\circledR}$ Total Knee System, which was recalled from the market in 2015 owing to high revision rates, had 18 PMA supplements approved via the 30-notice and 135-day review tracks alone. These supplements were largely for manufacturing process changes.

\section{Types of Postmarket Device Changes}

The types of device changes approved via the various PMA supplement review tracks largely correspond with the intended use of each review track. However, some discrepancies were present. The real-time process track is intended for minor design modifications and requires less new supporting preclinical data than the 180-day review. However, only $17 \%$ of design changes approved via realtime process were classified as minor. Furthermore, a large percentage of changes in device indications (46.2\%), were approved via real-time and 180-day tracks, despite that the changes in indication are intended to undergo formal panel track approval, which requires submission of new clinical data. For cardiac implantable electronic devices, the majority of real-time and 180-day track supplements were used for changes in device design or components $(76 \%)$ [21], whereas for orthopaedic devices, design and component changes accounted for only $41 \%$ of all 180-day track and real-time supplements. While the FDA has ultimate control over which supplement review tracks are used for device changes, there is potential for overuse of certain review tracks to expedite time to approval. In the future, the controls over what types of device changes are approved through the various supplement review tracks should be reviewed.

\section{Device Recalls and Market Withdrawal}

The high profile failure of the ASR ${ }^{\mathrm{TM}}$ XL Acetabular Cup System brought to light the inadequacies of the FDA's 510(k) premarket notification system [1]. Because the PMA process is more rigorous and thorough, fewer device failures should be expected. Now with the recent FDA recalls of the New Jersey LCS ${ }^{\circledR}$ Total Knee System for certain uses and certain sizes of the BHR ${ }^{\circledR}$ System owing to high revision rates, additional scrutiny of the PMA approval process and PMA supplements may be expected. Overall, most FDA recalls of PMA devices were not attributable to design flaws but rather issues with processing, packaging, or labeling. Nevertheless, with modern orthopaedic implants being designed for durability for up to decades, we may just now be understanding the longterm outcomes of these implants which were not previously studied for such periods. Because poor performance of these prostheses has been identified speaks to the effectiveness of current postmarket surveillance measures. Prospective registries such as the Australian Orthopaedic 
Association National Joint Replacement Registry, which identified higher revision rates with the New Jersey LCS ${ }^{\circledR}$ System [2], and Smith \& Nephew, which identified higher revision rates with smaller sizes of the $\mathrm{BHR}^{\circledR}$ system using data from the National Joint Registry of England and Wales [23], were able to rapidly notify manufacturers of poor outcomes and initiate a product recall.

Orthopaedic surgeons should be aware that even among high-risk medical devices cleared via the FDA's PMA pathway, considerable postmarket device modification occurs often without new supporting clinical data. This is particularly true given that new models of devices are rapidly incorporated in clinical practice [11]. Several studies have shown poor performance of various newly released orthopaedic devices without supporting premarket clinical data $[7,14,16]$. In addition, remarketing of new devices based on changes implemented via PMA supplements may permit devices that may be used for substantially different purposes than supported by original clinical evidence [34]. As a result, continued postmarket surveillance of high-risk orthopaedic devices is critical to ensure patient safety [5]. Although the quality of FDA-mandated postapproval studies has been questioned [19], efforts to build national and international orthopaedic device registries [15] and electronic health record-based monitoring systems $[8,17]$ are underway. Programs such as these may enable continued manufacturer innovation through least burdensome premarket regulation, while still maintaining sufficient postmarket oversight to limit patient safety risks.

\section{References}

1. Ardaugh BM, Graves SE, Redberg RF. The $510(\mathrm{k})$ ancestry of a metal-on-metal hip implant. N Engl J Med. 2013;368:97-100.

2. Austrailian Government Department of Health Therapeutic Goods Administration. LCS Complete RPS Knee System (used in knee replacements). 2015. Available at: https://www.tga.gov. au/alert/lcs-complete-rps-knee-system-used-knee-replacements. Accessed September 30, 2015.

3. Chen CE, Dhruva SS, Redberg RF. Inclusion of comparative effectiveness data in high-risk cardiovascular device studies at the time of premarket approval. JAMA. 2012;308:1740-1742.

4. Committee on the Public Health Effectiveness of the FDA Clearance Process. In: Wizemann T, ed. Public Health Effectiveness of the FDA 510(k) Clearance Process: Measuring Postmarket Performance and Other Select Topics: Workshop Report. Washington DC: National Academies Press; 2011.

5. Dhruva SS, Bero LA, Redberg RF. Strength of study evidence examined by the FDA in premarket approval of cardiovascular devices. JAMA. 2009;302:2679-2685.

6. Dhruva SS, Bero LA, Redberg RF. Gender bias in studies for Food and Drug Administration premarket approval of cardiovascular devices. Circ Cardiovasc Qual Outcomes. 2011;4:165171.

7. Fernandez-Valencia J, Gallart X, Bori G, Ramiro SG, Combalia A, Riba J. Assessment of patients with a DePuy ASR metal-onmetal hip replacement: results of applying the guidelines of the
Spanish Society of Hip Surgery in a tertiary referral hospital. Adv Orthop. 2014;2014:982523.

8. Forrow S, Campion DM, Herrinton LJ, Nair VP, Robb MA, Wilson $\mathrm{M}$, Platt R. The organizational structure and governing principles of the Food and Drug Administration's Mini-Sentinel pilot program. Pharmacoepidemiol Drug Saf. 2012;21(suppl 1):12-17.

9. Garber AM. Modernizing device regulation. $N$ Engl J Med. 2010;362:1161-1163.

10. Goodman SN, Redberg RF. Opening the FDA black box. JAMA. 2014;311:361-363.

11. Kesselheim AS, Avorn J. New and unproved medical devices. BMJ. 2013;347:f7413.

12. Kesselheim AS, Rajan PV. Regulating incremental innovation in medical devices. BMJ. 2014;349:g5303.

13. Kramer DB, Mallis E, Zuckerman BD, Zimmerman BA, Maisel WH. Premarket clinical evaluation of novel cardiovascular devices: quality analysis of premarket clinical studies submitted to the Food and Drug Administration 2000-2007. Am J Ther. 2010;17:2-7.

14. Kynaston-Pearson F, Ashmore AM, Malak TT, Rombach I, Taylor A, Beard D, Arden NK, Price A, Prieto-Alhambra D, Judge A, Carr AJ, Glyn-Jones S. Primary hip replacement prostheses and their evidence base: systematic review of literature. BMJ. 2013;347:f6956.

15. Maloney WJ. The role of orthopaedic device registries in improving patient outcomes. J Bone Joint Surg Am. 2011;93:2241.

16. Nieuwenhuijse MJ, Nelissen RG, Schoones JW, Sedrakyan A. Appraisal of evidence base for introduction of new implants in hip and knee replacement: a systematic review of five widely used device technologies. BMJ. 2014;349:g5133.

17. Platt R, Carnahan RM, Brown JS, Chrischilles E, Curtis LH, Hennessy S, Nelson JC, Racoosin JA, Robb M, Schneeweiss S, Toh S, Weiner MG. The U.S. Food and Drug Administration's Mini-Sentinel program: status and direction. Pharmacoepidemiol Drug Saf. 2012;21(suppl 1):1-8.

18. Redberg RF. Sham controls in medical device trials. $N$ Engl $J$ Med. 2014;371:892-893.

19. Reynolds IS, Rising JP, Coukell AJ, Paulson KH, Redberg RF. Assessing the safety and effectiveness of devices after US Food and Drug Administration approval: FDA-mandated postapproval studies. JAMA Intern Med. 2014;174:1773-1779.

20. Rome BN, Kramer DB, Kesselheim AS. Approval of high-risk medical devices in the US: implications for clinical cardiology. Current Cardiol Rep. 2014;16:489.

21. Rome BN, Kramer DB, Kesselheim AS. FDA approval of cardiac implantable electronic devices via original and supplement premarket approval pathways, 1979-2012. JAMA. 2014;311:385-391.

22. Sheth U, Nguyen NA, Gaines S, Bhandari M, Mehlman CT, Klein G. New orthopedic devices and the FDA. J Long Term Eff Med Implants. 2009;19:173-184.

23. Smith \& Nephew. Statement regarding BHR System. 2015. Available at: http://www.smith-nephew.com/news-and-media/ media-releases/news/statement-regarding-bhr-system/. Accessed September 23, 2015.

24. U.S. Food and Drug Administration. Federal Food, Drug, and Cosmetic Act. Available at: http://uscode.house.gov/view. xhtml?path=/prelim@title21/chapter9\&edition=prelim Accessed November 4, 2015.

25. U.S. Food and Drug Administration. Medtronic Recalls Sprint Fidelis Cardiac Leads: Questions and Answers for Consumers. Available at: http://www.fda.gov/ForConsumers/ConsumerUpdates/ucm103022. htm. Accessed September 23, 2015.

26. U.S. Food and Drug Administration. 515 Program Initiative. Available at: http://www.fda.gov/AboutFDA/CentersOffices/ OfficeofMedicalProductsandTobacco/CDRH/CDRHTransparency/ ucm240310.htm. Accessed September 26, 2015. 
27. U.S. Food and Drug Administration. PMA Supplements and Amendments. Available at: http://www.fda.gov/Medical Devices/DeviceRegulationandGuidance/HowtoMarketYourDevice/ PremarketSubmissions/PremarketApprovalPMA/ucm050467.htm. Accessed December 1, 2014.

28. U.S. Food and Drug Administration. Premarket Approval (PMA). Available at: http://www.fda.gov/Medicaldevices/Deviceregula tionandguidance/Howtomarketyourdevice/Premarketsubmissions/ Premarketapprovalpma/Default.Htm Accessed December 1, 2014.

29. U.S. Food and Drug Administration. Recalls, Corrections and Removals (Devices). U.S. Food and Drug Administration. Available at: http://www.fda.gov/MedicalDevices/DeviceRegulationandGuidance/ PostmarketRequirements/RecallsCorrectionsAndRemovals/. Accessed September 26, 2015.

30. U.S. Food and Drug Administration. 510(k) Clearances $>$ Downloadable 510(k) Files. Available at: http://www.fda.gov/Medical Devices/ProductsandMedicalProcedures/DeviceApprovalsand
Clearances/510kClearances/ucm089428.htm. Accessed January 15,2015

31. U.S. Food and Drug Administration. FDA Medical Device Recalls. Available at: https://www.accessdata.fda.gov/scripts/cdrh/ cfdocs/cfres/res.cfm. Accessed September 30, 2015.

32. U.S. Food and Drug Administration. Orthopaedic and Rehabilitation Devices Panel. Available at: http://www.fda.gov/Advisory Committees/CommitteesMeetingMaterials/MedicalDevices/Medical DevicesAdvisoryCommittee/OrthopaedicandRehabilitationDevices Panel/default.htm. Accessed January 15, 2015.

33. U.S. Food and Drug Administration. Premarket Approval (PMA) Database. Available at: http://www.accessdata.fda.gov/scripts/ cdrh/cfdocs/cfpma/pma.cfm. Accessed January 15, 2015.

34. Zheng SY, Redberg RF. Premarket approval supplement pathway: do we know what we are getting? Ann Intern Med. 2014;160:798799. 